\title{
Los incrementos de valor inconstitucionales en el Impuesto sobre el Incremento de Valor de los Terrenos de Naturaleza Urbana
}

\author{
Unconstitutional increases in value in the Capital Gains Tax \\ on Urban Land
}

\author{
Fernando Casana Merino \\ Universidad de Córdoba \\ dplcamef@uco.es
}

\begin{abstract}
RESUMEN
En los últimos meses tres Sentencias del Tribunal Constitucional han declarado inconstitucionales las normas que regulan la determinación de la base imponible del IIVTNU en Gipúzcoa, Álava y en todas las Comunidades Autónomas de régimen común. Este artículo analiza los antecedentes, el fundamento y las consecuencias de estas Sentencias, prestando especial atención a la declaración de inconstitucionalidad de varios preceptos del Texto Refundido de la Ley Reguladora de las Haciendas Locales y sus efectos para los ayuntamientos y los contribuyentes de las Comunidades Autónomas de régimen común.
\end{abstract}

\section{PALABRAS CLAVE}

Tribunal Constitucional, Tributos, Tributos locales, Impuesto sobre el Incremento de Valor de los Terrenos de Naturaleza Urbana.

\begin{abstract}
In recent months, three Sentences passed by Spain's Constitutional Court have deemed unconstitutional the regulations governing determination of the tax base for the Capital Gains Tax on Urban Land in Gipúzcoa, Álava and all the country's Autonomous Regions. This paper examines the background, rationale and consequences of these Sentences, focussing particularly on the ruling concerning the unconstitutional nature of several provisions contained in the Consolidated Text of the Law Regulating Local Public Finance and its repercussions for local councils and taxpayers in the Autonomous Regions.
\end{abstract}

\section{KEYWORDS}

Constitutional Court, Taxes, Local taxes, Tax on the increase in the value of the land.

\section{SUMARIO}

I. LA PROGRESIVA OBJETIVACIÓN EN EL CÁLCULO DE LA BASE IMPONIBLE DEL IIVTNU. II. LOS SUPUESTOS EN QUE SE GRAVAN PLUSVALÍAS IRREALES O FICTICIAS Y SU CONFIGURACIÓN EN EL MARCO DE LA RELACIÓN JURÍDICO-TRIBUTARIA. 1. EL GRAVAMEN DE PLUSVALÍAS FICTICIAS COMO UNA PRESUNCIÓN ABSOLUTA O COMO UNA FICCIÓN JURÍDICA. 2. LOS EFECTOS QUE TIENE EL GRAVAMEN DE PLUSVALÍAS FICTICIAS EN RELACIÓN CON LA NATURALEZA DEL IIVTNU: SU CONVERSIÓN EN UN TRIBUTO SOBRE LA RIQUEZA INMOBILIARIA 3. EL GRAVAMEN DE PLUSVALÍAS FICTICIAS Y EL HECHO IMPONIBLE DEL IIVTNU: SI NO HAY INCREMENTO DE VALOR NO HAY HECHO IMPONIBLE Y ESTAMOS ANTE UN SUPUESTO DE NO SUJECIÓN. III. ELEMENTOS SOBRE LOS QUE DEBE ASENTARSE EL JUICIO SOBRE LA CONSTITUCIONALIDAD EN EL GRAVAMEN DE PLUSVALÍAS INMOBILIARIAS FICTICIAS. 1. RESULTA IMPRESCINDIBLE DISTINGUIR ENTRE RENTA 
REALA. Nueva Época - N. ${ }^{\circ}$ 8, noviembre 2017 - ISSN: 1989-8975 - DOI: 10.24965/reala.v0i8.10445 - [Págs. 147-163]

Los incrementos de valor inconstitucionales en el Impuesto sobre el Incremento de Valor de los Terrenos de Naturaleza Urbana

Fernando Casana Merino

POTENCIAL Y RENTA FICTICIA. EL GRAVAMEN DE UNA RENTA POTENCIAL PUEDE SER INCONSTITUCIONAL SI RESULTA CONTRARIO A LA CAPACIDAD ECONÓMICA. EL GRAVAMEN DE UNA RENTA FICTICIA VULNERA SIEMPRE EL PRINCIPIO DE CAPACIDAD ECONÓMICA. 2. EL PRINCIPIO DE CAPACIDAD ECONÓMICA, ADEMÁS DE SER UN CRITERIO INSPIRADOR DEL SISTEMA TRIBUTARIO OPERA SINGULARMENTE RESPECTO DE CADA PERSONA. IV. LA DECLARACIÓN DE INCONSTITUCIONALIDAD DE LAS NORMAS QUE REGULAN LA DETERMINACIÓN DE LA BASE IMPONIBLE DEL IMPUESTO SOBRE EL INCREMENTO DE VALOR DE LOS TERRENOS DE NATURALEZA URBANA CUANDO GRAVEN UNA CAPACIDAD ECONÓMICA FICTICIA. 1. LA PRIMERA ADVERTENCIA SOBRE LA POSIBLE INCONSTITUCIONALIDAD DE LA REGULACIÓN DE LA BASE IMPONIBLE DEL IIVTNU: LA STC 221/1992. 2. LA DECLARACIÓN DE INCONSTITUCIONALIDAD DE LAS NORMAS QUE REGULAN LA BASE IMPONIBLE DEL IIVTNU CUANDO SU APLICACIÓN SUPONGA EL GRAVAMEN DE PLUSVALÍAS FICTICIAS: LAS SSTC 26/2017, 37/2017 Y 59/2017. 3. LA PECULIAR FORMA DE DECLARAR LA INCONSTITUCIONALIDAD DE LAS NORMAS QUE REGULAN LA BASE IMPONIBLE DEL IIVTNU: SON INCONSTITUCIONALES PERO SOLO EN FUNCIÓN DEL RESULTADO DE SU APLICACIÓN. 4. LA IMPRESCINDIBLE MODIFICACIÓN DEL TEXTO REFUNDIDO DE LA LEY REGULADORA DE LAS HACIENDAS LOCALES Y LA SOLUCIÓN DE LAS SITUACIONES GENERADAS POR LA INCONSTITUCIONALIDAD HASTA TANTO SE PRODUZCA LA MODIFICACIÓN. REFERENCIAS BIBLIOGRÁFICAS.

\section{LA PROGRESIVA OBJETIVACIÓN EN EL CÁLCULO DE LA BASE IMPONIBLE DEL IIVTNU}

La existencia de un tributo local sobre las plusvalías inmobiliarias data de 1919, fecha en la que mediante un Real Decreto de 13 de marzo se puso en vigor la Ley de Autorizaciones de 1917. Desde entonces, siempre ha existido un impuesto local sobre el incremento de valor de los terrenos urbanos, que primero recibió la denominación de Arbitrio de Plusvalías, y posteriormente, desde la Ley de Bases de Régimen Local de 1975, Impuesto sobre el Incremento del Valor de los Terrenos (en delante IIVT). Durante todo este tiempo el sistema de determinación de la base imponible no fue totalmente objetivo, sino que se basaba en la comparación de los valores del terreno al inicio y al final del período de cálculo de la plusvalía. Así, en la regulación inmediatamente anterior a la actual, que es la del Real Decreto Legislativo 781/1986, de 18 de abril, por el que se aprueba el texto refundido de las disposiciones legales vigentes en materia de Régimen Local (en adelante TRRL), la base imponible se calculaba por la diferencia entre el valor corriente en venta del terreno al comenzar y al terminar el período de imposición.

El valor corriente en venta del terreno no era un concepto totalmente subjetivo, sino que se determinaba aplicando los tipos unitarios aprobados por cada ayuntamiento en función del aprovechamiento urbanístico del terreno en cuestión. Estos tipos unitarios de valor corriente en venta de los terrenos formaban unos índices de valoración que, teóricamente, debían ser aprobados cada tres años por cada ayuntamiento atendiendo a la situación concreta del terreno. No obstante, el componente objetivo que podían representar los valores administrativos plasmados en los índices de valoración era ponderado con la introducción de elementos subjetivos de valoración. Así, el art. 355.4 del TRRL permitía no gravar la parte de incremento de valor que era debido al esfuerzo del propietario, pues las mejoras realizadas en el terreno y las contribuciones especiales devengadas incrementaban el valor inicial del terreno. Además, para evitar que la desvalorización monetaria llevase al gravamen de plusvalías ficticias, el apartado 5 del citado art. 355.4 del TRRL autorizaba al Gobierno, "cuando razones de política económica así lo exijan», para adoptar correcciones monetarias sobre el valor de adquisición y, en su caso, sobre el de las contribuciones especiales y mejoras permanentes. En resumen, el sistema de cálculo de la base imponible del IIVT partía de valores administrativos similares al valor catastral, pero esos valores podían ser corregidos tanto por la Administración como por el contribuyente y, podían ser impugnados en el momento de su aprobación, que tenía una validez inicial de tres años.

Con la entrada en vigor, el 1 de enero de 1990, de la Ley 38/1988, de 28 de diciembre, reguladora de las Haciendas Locales (en adelante LRHL), el Impuesto pasa a ser llamado Impuesto sobre el Incremento de Valor de los Terrenos de Naturaleza Urbana (en adelante IIVTNU), y se instaura un sistema de valoración totalmente objetivo que no admite correcciones. La base imponible del terreno, el incremento de valor, se determina por la aplicación de un porcentaje al valor catastral del terreno en el momento del devengo, y ese porcentaje se fija en función de elementos que no tienen una relación directa con el incremento ganado por un terreno concreto, como el número de años de generación de la plusvalía o el número de habitantes del municipio. Además, la LRHL se asegura que la magnitud resultante de la aplicación de los porcentajes previstos en ella no pueda ser alterada por los ayuntamientos al revisar la declaración ni de oficio, ni en vía de recurso. 
El art. 108 LRHL establecía que «la base imponible de este impuesto estará constituida por el incremento real del valor de los terrenos de naturaleza urbana...». Como quiera que el término «incremento real» parece que daba pie a que el contribuyente discutiese el resultado de la aplicación de las reglas legales cuando tenían como efecto el gravamen de plusvalías ficticias, la Ley 51/2002, de reforma de la LRHL, modifica el artículo 108, que queda redactado en los siguientes términos: «1. La base imponible de este impuesto estará constituida por el incremento de valor de los terrenos (...)». Desaparece, por tanto, el adjetivo «real» de la base imponible del IIVTNU y se da el paso definitivo para que puedan gravarse con pleno respaldo legal plusvalías irreales o ficticias. Esta es la definición de base imponible del IIVTNU que contiene el actual Texto Refundido de la Ley Reguladora de las Haciendas Locales, aprobado por el Real Decreto Legislativo 2/2004, de 5 de marzo (en adelante TRLRHL).

La regulación actual de la base imponible del IIVTNU, y que ha sido declarada inconstitucional, se asienta sobre dos pilares. En primer lugar, el incremento de valor solo puede determinarse mediante la aplicación de un porcentaje al valor del terreno en el momento del devengo. Este valor será el que tenga asignado el terreno en dicho momento a efectos del IBI. En segundo lugar, las competencias de gestión de los ayuntamientos se reducen a elegir entre el sistema de autoliquidación o el de liquidación administrativa. La comprobación de las declaraciones o autoliquidaciones presentadas no puede extenderse al cálculo del incremento o disminución de valor sufrido por el terreno, sino a si se han aplicado o no correctamente las normas que establece el TRLRHL para determinar la base imponible. Según dispone el art. 110.4 TRLRHL «los ayuntamientos quedan facultados para establecer el sistema de autoliquidación por el sujeto pasivo, que llevará consigo el ingreso de la cuota resultante de aquella dentro de los plazos previstos en el apartado 2 de este artículo. Respecto de dichas autoliquidaciones, el ayuntamiento correspondiente solo podrá comprobar que se han efectuado mediante la aplicación correcta de las normas reguladoras del impuesto, sin que puedan atribuirse valores, bases o cuotas diferentes de las resultantes de tales normas».

\section{LOS SUPUESTOS EN QUE SE GRAVAN PLUSVALÍAS IRREALES O FICTICIAS Y SU CONFIGURACIÓN EN EL MARCO DE LA RELACIÓN JURÍDICO-TRIBUTARIA}

\section{El gravamen de plusvalías ficticias como una presunción absoluta o como una ficción jurídica}

La aplicación de normas tributarias que afectan a los elementos esenciales del tributo de forma presuntiva o no expresa puede revestir distintas formas. El mecanismo presuntivo puede operar como consecuencia de la aplicación directa de una disposición legal o como resultado de la interpretación de una norma. En el primer caso se habla de presunciones legales y en el segundo de presunciones deductivas, que son aquellas realizadas por el intérprete y aplicador de la norma cuando existe un nexo causal entre el hecho demostrado y aquel que se trata de deducir. El gravamen de plusvalías inmobiliarias ficticias resulta de la aplicación del TRLRHL por lo que, de ser una presunción, sería una presunción legal.

Las presunciones legales hacen referencia a hechos definidos en la norma, de cuya realización se deriva por ministerio de la ley, la consecuencia de entenderse producido un hecho diferente. Cuando la doctrina trata de las presunciones legales suele distinguir entre presunciones simples o iuris tantum y absolutas o iuris et de iure, según que admitan o no prueba en contrario. Las presunciones simples liberan de la carga de la prueba al favorecido por ellas y las presunciones absolutas impiden la prueba en contra del resultado de la presunción. Una figura muy cercana a la de las presunciones iuris et de iure es la de las ficciones. Tanto la presunción absoluta como la ficción excluyen la posibilidad de probar, pero mientras que la aplicación de una presunción no siempre tiene como resultado la validación jurídica de un hecho inexistente, la ficción conlleva la creación de una irrealidad. Puede decirse que las ficciones jurídicas producen el mismo efecto que las presunciones absolutas, pero además suponen el otorgamiento de validez jurídica a un hecho irreal. Como escribe el profesor ESEVERRI (1995), «la ficción jurídica parte como evidencia de la inexistencia de un hecho y a través de ella se crea una realidad jurídica -por ahí su denominación-, ya que la norma jurídica que la contempla basándose en un presupuesto falso o de difícil constatación lo sustituye por una realidad que, consecuentemente, hay que tomarla por una realidad artificial no discutible» (negrita en el original) (ESEVERRI MARTÍNEZ, 1995: 21).

Como escribe GUTIÉRREZ BENGOECHEA «la distinción [entre presunción y ficción] quizás hay que verla en el plano metajurídico, es decir si observamos o nos atenemos a un momento anterior a su plasmación legislativa. 
En este caso el legislador al introducir la presunción tendrá que partir de la realidad de un hecho del que se infiere o se presume otro; sin embargo, la ficción nace de una irrealidad» (GUTIÉRREZ BENGOECHEA, 2012: 48).

Además de las diferencias ya citadas, en el aspecto procesal, la parte favorecida por una presunción puede dejar de utilizarla, pero en ningún caso puede dejar de aplicarse la ficción jurídica, pues es una norma de obligado cumplimiento. A pesar de estas diferencias que afectan a la naturaleza jurídica de ambas figuras, sus efectos son los mismos. La ficción y la presunción absoluta se sitúan extramuros de la institución de la prueba -excluyen la utilización de la prueba-, aunque la aplicación de la presunción no siempre concede validez jurídica a un hecho o situación artificial o irreal (realidad virtual). Puede decirse que tanto las ficciones como las presunciones absolutas impiden probar que la realidad es distinta a la que resulta de su aplicación, aunque no todas las presunciones absolutas tienen como resultado la validación jurídica de un hecho o situación que carece de existencia real, cosa que sí ocurre en las ficciones.

Una parte de la doctrina y de la jurisprudencia de los Tribunales Superiores de Justicia han entendido que la norma que regula el sistema de cálculo de la base imponible del IIVTNU produce los efectos de una ficción jurídica o de una presunción iuris et de iure. Así, expone ORÓN MORATALL que «al no haber una comparación entre los valores inicial y final siempre existirá incremento de valor, incremento que es presunto, surgiendo el problema de si esa presunción es iuris tantum y admite prueba en contrario, o es iuris et de iure y no la admite, problema que puede entenderse resuelto en el sentido de no admitir prueba en contrario desde el momento en que la Ley ya no se refiere al incremento real del valor» (ORÓN MORATALL, 2010: 733). Por lo que respecta a la jurisprudencia, entre otras, la STSJ de Castilla y León (Valladolid) de 3 de marzo de 1999 (núm. de recurso 1002/1995) (núm. de resolución 269/1999) expone en su FD Primero que la fijación de la base imponible se objetiva «mediante un método legal, presuntivo y simple, que no tiene en cuenta en modo alguno si tal plusvalía es la realmente producida en el caso concreto o no». Y en el mismo sentido la STSJ de Canarias (Las Palmas) de 3 de septiembre de 1999 (núm. de recurso 238/1997) (núm. de resolución 1184/1999) se refiere de forma expresa al término ficción, afirmando que «en este Impuesto - de clara naturaleza patrimonial y no rediticia- el incremento gravado es fruto de una ficción jurídica, pues resulta de unas reglas de valoración que fija la Ley y que, a salvo el supuesto excepcional antes señalado [de impugnación del valor castastral], impide cualquier acción del sujeto pasivo para demostrar que aquélla magnitud no se corresponde con la que derive de aplicar los preceptos legales» (FD Cuarto). Y más recientemente la STSJ de Andalucía (Granada) de 4 de marzo de 2002 (núm. de recurso 5/1997) (núm. de resolución 250/2002), en su FD Segundo después de exponer las distintas tesis utilizadas por los Tribunales Superiores de Justicia sobre la naturaleza de esta figura (presunción absoluta, ficción jurídica, presunción relativa o, mandato legal de carácter no presuntivo) manifiesta que la postura mantenida por la Sala es «que nos hallamos en presencia de una regla de valoración, cuya característica esencial estriba en que es la propia ley quien determina el valor de un determinado bien o derecho a los efectos de su cómputo en la base imponible»; ... añadiendo que «La esencial característica de este tipo de normas, es que contienen un mandato imperativo de inexcusable cumplimiento, mandato que, además, está desconectado de las reglas que pudieran operar a propósito de la prueba de los hechos». Aunque la citada STSJ de Andalucía (Granada) de 4 de marzo de 2002 (núm. de recurso 5/1997) no lo diga expresamente, el resultado de las argumentaciones que contiene es que la determinación de la base imponible en el IIVTNU se realiza mediante una ficción, pues su aplicación conduce a gravar una magnitud a la que se llama incremento de valor que nada tiene que ver con el que realmente ha experimentado el inmueble.

\section{Los efectos que tiene el gravamen de plusvalías ficticias en relación con la naturaleza del IIVTNU: su conversión en un tributo sobre la riqueza inmobiliaria}

La consecuencia de que la norma que regula la base imponible en el IIVTNU no admite prueba en contrario no es solo que el IIVTNU grava incrementos de valor irreales, sino que desvirtúa la naturaleza de dicho tributo. Desde su creación en 1919, el Impuesto de Plusvalías, posteriormente llamado Arbitrio sobre el Incremento de Valor de los Terrenos e Impuesto sobre el Incremento del Valor de los Terrenos siempre ha establecido un sistema de cálculo de la base imponible que permitía la comparación de los valores del terreno transmitido al principio y al final del período de generación de la plusvalía. En algunas épocas este sistema se objetivó en gran medida, utilizando los valores de adquisición y transmisión aprobados por los ayuntamientos en unas tablas oficiales a las que se llamaba índices de valoración, pero siempre se admitió 
REALA. Nueva Época - N. ${ }^{\circ}$ 8, noviembre 2017 - ISSN: 1989-8975 - DOI: 10.24965/reala.v0i8.10445 - [Págs. 147-163]

Los incrementos de valor inconstitucionales en el Impuesto sobre el Incremento de Valor de los Terrenos de Naturaleza Urbana

Fernando Casana Merino

la posibilidad de probar que los valores administrativos no eran reales. La oportunidad de probar en contra de los valores oficiales desaparece con la LHL de 1988, que impide al obligado tributario demostrar que el incremento de valor no ha existido o ha sido distinto del que resulta de las normas legales, y se afianza como una ficción en 2002, cuando se suprime el término «incremento real» de la definición de la base imponible. La consecuencia del sistema de valoración del incremento de valor instaurado por la LHL y por el TRLHL es que durante más de treinta años se ha venido aplicando un impuesto que no grava las plusvalías inmobiliarias, sino la titularidad del bien cada cierto número de años. Lo reconoce la Dirección General de Tributos, que en la Consulta Vinculante V0153-14, de 23 de enero de 2014 deja bien claro que «La regla de determinación de la base imponible del IIVTNU establecida por el TRLRHL no es una presunción ni una regla probatoria, sino una regla de valoración que permite cuantificar la base imponible a través de un método objetivo [la cursiva es nuestra]. El impuesto no somete a tributación una plusvalía real, sino una plusvalía cuantificada de forma objetiva» ${ }^{\text {. }}$ Para la Dirección General de Tributos no hay duda de que la regla de valoración de la base ni admite prueba en contrario ni es susceptible de no aplicación (lo que la convierte en una ficción jurídica), explicando a continuación la citada Consulta Vinculante V0153-14 que «el fundamento de este impuesto no es tanto gravar el incremento "real" provocado por el titular del terreno por diferencia entre unos precios de venta y compra, sino que trata de gravar el incremento de valor del terreno como consecuencia de la acción urbanística del propio municipio donde se encuentra (instalación o mejora de alumbrado público, aceras, mobiliario urbano, etc.)». A mi juicio, el fundamento del IIVTNU es el que señala la Dirección General de Tributos en la citada Consulta V0153-14, y ese fundamento entronca con el art. $47 \mathrm{CE}$, lo que ocurre es que la regulación actual no responde a ese fundamento constitucional. El sistema de valoración de la base no solo no grava el incremento de valor de los terrenos urbanos en el mercado, sino que tampoco grava la parte de incremento que se debe o puede deberse a la acción urbanística de los entes públicos. En definitiva, la base imponible del IIVTNU en su regulación actual es una magnitud que nada tiene que ver con el incremento o disminución en el valor de un terreno, que tampoco tiene que ver con el posible aumento de valor debido a la acción urbanística de los entes públicos, y que como el Impuesto se devenga periódicamente (lo cual no quiere decir que sea periódico) y se aplica sobre una parte del valor catastral, produce como efecto que el IIVTNU se ha convertido en un tributo sobre la riqueza inmobiliaria con similitudes en cuanto al objeto gravado con el Impuesto sobre el Patrimonio y con el Impuesto sobre Bienes Inmuebles.

\section{El gravamen de plusvalías ficticias y el hecho imponible del IIVTNU: si no hay incremento de valor no hay hecho imponible y estamos ante un supuesto de no sujeción}

En lo que respecta a la determinación de la base imponible del IIVTNU, el TRLRHL no admite lugar a dudas: el terreno siempre estará sometido a gravamen aunque haya bajado de valor, y el ayuntamiento al liquidar o al comprobar la autoliquidación solo puede limitarse a constatar que se han aplicado correctamente los porcentajes que establece la Ley. A pesar de que la normativa es clara y no genera dudas, los excesos y absurdos a que conduce su aplicación han llevado a que una gran parte de la doctrina, apoyándose en una jurisprudencia del Tribunal Supremo referida a la legislación anterior y en la de algunos TSJ que aplicaban la LRHL, sostenga en contra de la contundencia de los términos legales, que el obligado tributario puede probar que no ha existido incremento de valor, y que, en tal caso, estaríamos ante un supuesto de no sujeción. Esta opinión ha sido mantenida insistentemente por muchos autores desde que se aprobó la LRHL de 1988 (entre otros autores, han defendido la no sujeción en los supuestos en los que el terreno no ha aumentado de valor entre el comienzo y la finalización del período de generación de la plusvalía: BRIS GÓMEZ, 2015: 148; HERNÁNDEZ LAVADO,1991: 83; SÁNCHEZ GALIANA y CALATRAVA ESCOBAR, 1993: 861; SÁNCHEZ GALIANA, Carlos M. ${ }^{a}, 2010:$ 64). Así, escribe MOCHÓN LÓPEZ: «Hay que afirmar: que la ausencia de plusvalía en la transmisión de los terrenos o en la constitución o transmisión de los derechos reales se trata de un supuesto de no sujeción»; y concluye más adelante que «En el IIVTNU el hecho normativo contiene como elemento integrante de él una referencia a que se haya producido un incremento de valor, exigencia que debe cumplir el hecho real para quedar sujeto» (MOCHÓN LÓPEZ, 2001: 274-275). Entre los trabajos más recientes, y en el mismo sentido, escribe MARTíN RUIZ que «desde un punto de vista técnico, hay que entender que en el caso de que el valor de transmisión de un terreno de naturaleza urbana sea inferior al de

1 Secretaría de Estado de Hacienda. Dirección General de Tributos [sitio web]. Doctrina tributaria. Consultas tributarias 19972017. Disponible en $h$ ttp://petete.minhafp.gob.es/consultas/. 
REALA. Nueva Época - N. ${ }^{\circ}$ 8, noviembre 2017 - ISSN: 1989-8975 - DOI: 10.24965/reala.v0i8.10445 - [Págs. 147-163]

Los incrementos de valor inconstitucionales en el Impuesto sobre el Incremento de Valor de los Terrenos de Naturaleza Urbana

Fernando Casana Merino

adquisición, simplemente, estamos ante un supuesto de no sujeción: no hay incremento y, por tanto, no se ha realizado el hecho imponible» (MARTÍN RUIZ, 2017: 57-58).

La jurisprudencia del Tribunal Supremo que aplicó el IIVT regulado por el TRRL 781/1986 se pronunció con claridad en favor de que en los supuestos de inexistencia de plusvalía se producía una no sujeción. Así la STS de 29 de abril de 1996 (rec. de casación núm. 3.279/1993) argumenta que «siendo el incremento del valor el objeto del gravamen, conforme a lo establecido en el art. 350 del Real Decreto Legislativo 781/1986, resulta evidente que si dicha "plus-valía" no se produce de manera efectiva y acreditada, ni puede razonablemente presumirse, atendidas las circunstancias objetivas concurrentes en el período de la imposición, no puede hablarse de sujeción al impuesto, que no es una mera fórmula de aplicación automática, tendente a la recaudación de un porcentaje sobre las diferencias que arrojen las cifras de valor formal separadas por un período de tiempo entre dos enajenaciones» (FD Segundo). En el mismo sentido, y también bajo el imperio del TRRL de 1986, la STS de 25 de febrero de 1997 (rec. núm. 336/1993) considera que «resulta evidente que si dicha "plus-valia" no se produce de manera efectiva y acreditada, ni puede razonablemente presumirse, atendidas las circunstancias objetivas concurrentes en el período de la imposición, no puede hablarse de sujeción al impuesto, que no es una mera fórmula de aplicación automática, tendente a la recaudación de un porcentaje sobre las diferencias que arrojen las cifras de valor formal separadas por un período de tiempo entre dos enajenaciones». En el caso resuelto por la STS de 25 de febrero de 1997 (rec. núm. 336/1993), durante el período de generación de la plusvalía gravable se produjo una suspensión de licencias, modificándose también el Plan General de Ordenación Urbana que determinó un cambio en la calificación del terreno transmitido, con lo que quedó inutilizable para aprovechamientos edificatorios particulares, admitiendo que la transmisión, en este caso, no está sujeta al IIVTNU (FD Segundo).

Y en el mismo sentido la STS de 30 de noviembre de 2000 (rec. cas. núm. 2306/1995) admite que en los casos en que los índices de valoración aprobados por el ayuntamiento no reflejen el valor actual del terreno (porque se calcularon teniendo en cuenta un aprovechamiento urbanístico aplicable a las construcción de bloques y el terreno en cuestión es inedificable) resultando de los informes periciales que tiene un aprovechamiento urbanístico cero, «resulta absurdo que [el IMIVT] recaiga sobre los posibles aumentos del precio de un terreno en el que la propia actividad administrativa ha hecho imposible que se edifique, pues es evidente que tales incrementos de valor, si llegan a producirse, tendrán otro origen, extraño a las motivaciones del tributo, produciéndose un supuesto de no sujeción» (FD Cuarto].

No obstante, hay que tener en cuenta que estas Sentencias se dictaron aplicando el TRRL de 1986, en el que se decía expresamente que el objeto del Impuesto era el incremento de valor experimentado por los terrenos durante el período de imposición. La redacción actual del art. 104 TRLRHL dice que el IIVTNU grava «el incremento de valor que experimenten dichos terrenos», y ese incremento de valor según el art. 107.1 TRHL sólo puede determinarse mediante la aplicación de un porcentaje al valor catastral del terreno en el momento del devengo. Además, el sistema de cálculo de la base imponible en el TRRL de 1986 no era el mismo que el que actualmente regula el vigente TRLRHL. El art. 355 del TRRL establecía que «1. La base del Impuesto será la diferencia entre el valor corriente en venta del terreno al comenzar y al terminar el período de imposición». El valor corriente en venta de un terreno debía ser fijado con arreglo a los índices de valoración que periódicamente (cada tres años) debía aprobar cada ayuntamiento teniendo en cuenta las características específicas, la situación del terreno y el aprovechamiento urbanístico del mismo. Por tanto, en el sistema del TRRL había más elementos que en la regulación actual para entender que cuando no había plusvalía el Impuesto carecía de objeto, y que cuando el valor resultante de los índices de valoración del ayuntamiento no tenía en cuenta el aprovechamiento urbanístico, no respondía al concepto de valor corriente en venta del terreno que era el exigido legalmente, por lo que podía dejar de aplicarse.

La jurisprudencia que aplicando la normativa actual declara que el IIVTNU no puede devengarse cuando el terreno ha bajado de valor desde la anterior transmisión es de los Tribunales Superiores de Justicia y de los Juzgados de lo Contencioso-Administrativo, que aplican la LHL de 1988 o el actual TRLRHL. La STSJ de la Comunidad Valenciana de 20 de julio de 2015 (rec. de apelación núm. 23/2015) identifica el incremento de valor a que se refiere la LHL como base imponible del IIVTNU con ganancia patrimonial efectiva, y añade que cuando se transmite el terreno con pérdida patrimonial no se produce el hecho imponible y ello impide cualquier determinación de la base (FD Cuarto). En el mismo sentido, aunque de forma más explícita en cuanto a sus consecuencias, se manifiesta una doctrina que arranca de la STSJ de Cataluña de 22 de marzo de 2012 (núm. de recurso 511/2011) que en su FD Cuarto expone el resultado de la doctrina de la no sujeción en los casos de inexistencia de incremento. Estas consecuencias son las siguientes: 
«1. ${ }^{a}$ Cuando se acredite y pruebe que en el caso concreto no ha existido, en términos económicos y reales, incremento alguno, no tendrá lugar el presupuesto de hecho fijado por la ley para configurar el tributo (art. 104.1 LHL), y éste no podrá exigirse, por más que la aplicación de las reglas del art. 107.2 siempre produzca la existencia de teóricos incrementos.

2. ${ }^{a}$ De la misma forma, la base imponible está constituida por el incremento del valor de los terrenos, el cual ha de prevalecer sobre lo que resulte de la aplicación de las reglas del art. 107, que sólo entrarán en juego cuando el primero sea superior. Por tanto, seguirá siendo de aplicación toda la jurisprudencia anterior sobre la prevalencia de los valores reales, pudiendo acudirse incluso a la tasación pericial contradictoria, en los casos en los que se pretenda la existencia de un incremento del valor inferior al que resulte de la aplicación del cuadro de porcentajes del art. 107. En esta hipótesis, la base imponible habrá de ser la cuantía de tal incremento probado, sin que sea admisible acudir a fórmulas híbridas o mixtas, que pretendan aplicar parte de las reglas del art. 107 al incremento probado».

Esta misma argumentación es recogida por numerosas Sentencias de TSJ posteriores ${ }^{2}$, como la STSJ de Cataluña de 1 de septiembre de 2016 (rec. contencioso-administrativo núm. 55/2015) (FD Tercero), que añade como corolario: «En suma, si no ha existido, en términos económicos y reales, incremento alguno, no tendrá lugar el presupuesto de hecho fijado por la ley para configurar el tributo (artículo 104.1 de la LHL) y éste no podrá exigirse, por más que la aplicación de las reglas del artículo 107.2 siempre produzca la existencia de teóricos incrementos» ${ }^{3}$.

No obstante, también hay Sentencias recientes de los TSJ que niegan la posibilidad de probar la inexistencia de incremento de valor y, por tanto la no sujeción. Así, aplicando la Norma Foral de Vizcaya, la STSJ del País Vasco de 24 de octubre de 2016 (rec. de apelación 298/2015) argumenta que «...la remisión que el artículo 4.2.a) de la Norma Foral del IIVTNU hace al valor del terreno que esté determinado en el momento del devengo a efectos del Impuesto sobre Bienes Inmuebles, constituye un elemento normativo y reglado de determinación de las bases que no forma parte del componente fáctico de la norma y que no abre paso a la estimación directa y contradictoria de la misma ni puede ser probatoriamente desvirtuado por los sujetos pasivos del tributo» (FD Segundo) ${ }^{4}$. También el TSJ de Aragón se ha manifestado en contra de admitir la prueba de que el incremento no ha existido o ha sido inferior al legal. Entre las más recientes, la STSJ de Aragón de 21 de diciembre de 2016 (rec. contencioso-administrativo núm. 42/2016) argumenta que «el artículo 107 de la Ley establece una regla de determinación de la base que no pretende medir realmente el incremento de valor de los terrenos, sino proporcionar un instrumento simplificado de cálculo de fácil aplicación a todos los interesados, no se somete pues a tributación una plusvalía real, sino una plusvalía cuantificada de forma objetiva por lo que todos los elementos de su configuración han sido fijados partiendo de esta premisa, de forma que solo con el planteamiento de una cuestión de inconstitucionalidad podría dejar de aplicarse la norma» (FD Tercero) ${ }^{5}$.

En mi opinión, la normativa del IIVTNU no ofrece lugar a dudas en el sentido de que no permite probar que un terreno no ha aumentado de valor o que el aumento es inferior al establecido en la norma legal. No

2 Idénticos argumentos conclusivos se reproducen en diversas Sentencias de la Sección Novena del TSJ de Madrid, entre otras en las Sentencias de 8 de octubre de 2015 (rec. de apelación 841/2014) (FD Tercero), de 21 de octubre de 2015 (rec. de apelación 1.034/2014) (FD Quinto) y de 27 de abril de 2016 (rec. de apelación 912/2015) (FD Quinto). Con idénticos argumentos se manifiesta también la STSJ de Cataluña de 9 de mayo de 2012 (rec. contencioso-administrativo núm. 501/2011) (FD Cuarto).

3 A la no sujeción cuando no existe incremento de valor efectivo o este es inferior al que resulta de la aplicación de las normas legales, se refiere también la STSJ de Madrid de 11 de diciembre de 2013 (rec. de apelación 767/2013), que en su FD Cuarto expone: «Sin perjuicio de lo expuesto, en los fundamentos anteriores, parece evidente que la ausencia objetiva del incremento del valor dará lugar a la no sujeción del impuesto, simplemente como consecuencia de la no realización del hecho imponible, pues la contradicción legal no puede ni debe resolverse a favor del "método de cálculo" y en detrimento de la realidad económica, pues ello supondría desconocer los principios de equidad, justicia y capacidad económica.

La misma conclusión ha de aplicarse cuando sí ha existido incremento de valor, pero la cuantía de éste es probadamente inferior a la resultante de la aplicación de dicho método de cálculo, al infringirse los mismos principios».

4 En el mismo sentido, y aplicando la Norma Foral de Navarra, se manifiesta la SJCA núm. 2 de Pamplona de 13 de julio de 2014 (rec. contencioso-administrativo núm. 195/2013), que apunta la idea de que cuando la pérdida de valor del terreno «no se debe a una actuación administrativa, sino a la evolución negativa de la coyuntura económica, el propietario que adquirió voluntariamente el terreno y, que de ser positiva dicha coyuntura se hubiera beneficiado de la revalorización del mismo, debe asumir también el riesgo de una rentabilidad negativa por la depreciación de sus propiedades, sin derecho a compensación» (FD Tercero).

5 Los mismos argumentos son repetidos por otras Sentencias del TSJ de Aragón. Así la STSJ de Aragón de 12 de diciembre de 2016 (rec. de apelación 142/2015) argumenta que «la regulación vigente no prevé que la base imponible sea el incremento real del valor de los terrenos, como diferencia entre el valor inicial y final del terreno y a través de la aplicación de fórmulas de matemática financiera concretas, sino el incremento que resulte de lo establecido en el art. 107 del TRLRHL» (FD Primero); y en idéntico sentido se manifiesta la STSJ de Aragón de 23 de diciembre de 2016 (rec. contencioso-administrativo núm. 49/2016) (FD Primero). 
REALA. Nueva Época - N. ${ }^{\circ}$ 8, noviembre 2017 - ISSN: 1989-8975 - DOI: 10.24965/reala.v0i8.10445 - [Págs. 147-163]

Los incrementos de valor inconstitucionales en el Impuesto sobre el Incremento de Valor de los Terrenos de Naturaleza Urbana

Fernando Casana Merino

obstante, la aplicación taxativa y sin excepción de los preceptos legales puede llevar a resultados abusivos y contrarios a la equidad. Esta es la razón de que tanto la doctrina como una parte de la jurisprudencia, a mi juicio realizando una interpretación forzada del TRLRHL, permitan que se pruebe la inexistencia de incremento efectivo de valor mediante la comparación de los valores del terreno en los momentos de inicio y finalización del período de generación de la plusvalía. No obstante, estas doctrinas, que sin duda tienen nuestro apoyo pues evitan consecuencias absurdas e injustas en la aplicación del IIVTNU, chocan con la redacción literal del TRLRHL. Esta es la situación que existía cuando se dictan diversas Sentencias del Tribunal Constitucional que declaran la nulidad de los preceptos legales que regulan la base imponible del IIVTNU y que comentamos a continuación.

\section{ELEMENTOS SOBRE LOS QUE DEBE ASENTARSE EL JUICIO SOBRE LA CONSTITUCIONALIDAD EN EL GRAVAMEN DE PLUSVALÍAS INMOBILIARIAS FICTICIAS}

1. Resulta imprescindible distinguir entre renta potencial y renta ficticia. El gravamen de una renta potencial puede ser inconstitucional si resulta contrario a la capacidad económica. El gravamen de una renta ficticia vulnera siempre el principio de capacidad económica

Las SSTC 26/2017, 37/2017 y 59/2017 han declarado respectivamente la inconstitucionalidad de los sistemas establecidos para la determinación de la base imponible en la Norma Foral de Guipúzcoa, en la Norma Foral de Álava y en el TRLRHL. Estos tres sistemas, en lo que se refiere a los criterios aplicables para la determinación de la base imponible son sustancialmente idénticos. La inconstitucionalidad va referida al incremento de valor como renta ficticia, concepto que debe distinguirse del de renta potencial, aunque ambas son rentas irreales.

El incremento de valor experimentado por un terreno durante un período temporal es una forma de renta que se incluye entre las plusvalías, ganancias patrimoniales o incrementos de valor. Las plusvalías inmobiliarias pueden ser sometidas a gravamen por distintos impuestos, y ello no es inconstitucional, pero en todo caso al hacerlas tributar se debe estar gravando una capacidad económica real o potencial. Por tanto, gravar un incremento de valor que no es ni puede ser nunca representativo de capacidad económica alguna resulta inconstitucional. Más adelante volveremos sobre esta idea apoyándonos en la jurisprudencia constitucional.

Para determinar cuándo una renta es representativa o no de capacidad económica es necesario distinguir entre renta ficticia y renta presunta o potencial. Ninguno de estos dos tipos de renta es representativo de una ganancia efectiva obtenida por el obligado tributario, pero mientras que la renta presunta pudo haber sido obtenida de haber sido distinta la actividad del contribuyente, la renta ficticia nunca podría haberse obtenido, pues los hechos en los que se basa son irreales, y el resultado es una renta irreal. Dice MARTíN RUIZ que «Ficticia sería una renta que ni existe, ni puede llegar a existir, es decir, una renta creada por el legislador a los solos efectos de hacer tributar al contribuyente sobre ella. En cambio, una renta potencial es aquella que puede ser que no exista en un caso concreto, pero podría llegar a existir si el contribuyente no renunciara a su obtención» (MARTÍN RUIZ, 2017: 54). Son rentas potenciales las rentas inmobiliarias imputadas, o el gravamen de las ganancias patrimoniales en el IRPF cuando se toma, de acuerdo con el art. 35 de la Ley del IRPF, como valor de enajenación el valor de mercado y este resulta superior al efectivamente satisfecho. En ambos casos, se grava una renta que el obligado tributario no ha obtenido efectivamente, pero que podría haberlo hecho de haber desarrollado una actividad distinta. En el caso de las rentas potenciales o presuntas el obligado tributario ha renunciado a percibir una renta que podría haber obtenido. En el caso de la renta imputada, el contribuyente podría haber arrendado el inmueble, y en el caso de la ganancia patrimonial, podría haber vendido el bien por su valor de mercado y no por un valor inferior como ha hecho.

El Tribunal Constitucional ha declarado en diversas ocasiones que el gravamen de rentas potenciales no es contrario a la capacidad económica. Entre las más recientes, la STC 295/2006 admite que es conforme con la Constitución el gravamen de rentas potenciales, dejadas de obtener como consecuencia de la renuncia o dejación por parte de su titular, como es el caso de las rentas inmobiliarias imputadas. La duda de inconstitucionalidad planteada en la STC 295/2006 hace referencia a la posible inconstitucionalidad de la forma de gravar estas rentas imputadas en el IRPF regulado por la Ley 18/1991, que determinaba el rendimiento gravable mediante la aplicación de un porcentaje al valor del inmueble en el Impuesto sobre el Patrimonio. Desde la Ley 44/1978 la renta presunta de los inmuebles desocupados se había determinado mediante la aplicación de un porcentaje al valor catastral, que siempre era un valor fijo. Con la Ley 18/1991, 
REALA. Nueva Época - N. ${ }^{\circ}$ 8, noviembre 2017 - ISSN: 1989-8975 - DOI: 10.24965/reala.v0i8.10445 - [Págs. 147-163]

Los incrementos de valor inconstitucionales en el Impuesto sobre el Incremento de Valor de los Terrenos de Naturaleza Urbana

Fernando Casana Merino

al tomar como valor de referencia el Impuesto sobre el Patrimonio este valor no es fijo, sino el mayor de tres (el catastral, el comprobado por la Administración, y el precio, contraprestación o valor de adquisición). El sistema consistente en aplicar un porcentaje a un valor que variaba en función de las circunstancias desapareció con el Real Decreto-Ley 12/1995, que restableció como único valor de referencia para cuantificar la renta imputada el valor catastral.

La remisión al valor del Impuesto sobre el Patrimonio suponía la aplicación de la regla del mayor valor entre los tres posibles, con lo que ante capacidades económicas idénticas, el sujeto era gravado en mayor o menor medida en función de la fecha y forma de adquisición del inmueble vacío, y no de las características de este. EI FJ 7 de la STC 295/2006 niega la posibilidad de justificar que la norma de la Ley 18/1991 no es contraria al principio de igualdad porque tiene una vocación general y uniforme. Dice el FJ 7 de la STC 295/2006 que «una cosa es que, conforme a nuestra doctrina, no pueda declararse la inconstitucionalidad de una norma por la circunstancia de que incurra en la vulneración del derecho a la igualdad "en supuestos puntuales" (SSTC 47/2001, de 15 de febrero [RTC 2001, 47] , F. 7; 212/2001, de 29 de octubre [RTC 2001, 212] , F. 5; 21/2002, de 28 de enero [RTC 2002, 21] , F. 4; y 255/2004, de 23 de diciembre [RTC 2004, 255], F. 4), y otra muy distinta es que deba declararse la conformidad con la Constitución de una norma tributaria que establece, en la generalidad de los casos, una discriminación contraria al principio de igualdad del art. 31.1 CE por el solo hecho de que "tenga vocación de generalidad y aplicación uniforme"». Es decir, el hecho de que no sea inconstitucional una norma cuya aplicación vulnera puntualmente el principio de igualdad no permite deducir que es constitucional toda norma que tenga una vocación de generalidad y uniformidad. Según la doctrina del Tribunal Constitucional, la norma puede ser contraria a la igualdad tributaria en supuestos puntuales y ello no la hace inconstitucional, pero de ahí no puede deducirse que toda norma que tenga una vocación de generalidad no conculca la igualdad y no es inconstitucional por el mero hecho de que sea de aplicación general y uniforme. Concluye el FD 8 de la referida STC 295/2006 que la renta imputada en los inmuebles no arrendados debe ser la misma ante inmuebles idénticos, y que carece de toda justificación y es contraria a la igualdad tributaria, la diferente imputación de renta mediante «la utilización de un diferente criterio para la cuantificación de los rendimientos frente a iguales manifestaciones de capacidad económica», dependiendo «de que se haya o no producido un acto dispositivo por parte del titular o actuaciones administrativas dirigidas a su valoración».

No entra a enjuiciar la STC 295/2006 la posible constitucionalidad del gravamen de rentas ficticias -posibilidad a la que hacen referencia en sus alegaciones el Fiscal General del Estado y el TSJ del País Vasco que plantea la cuestión de inconstitucionalidad (FJ 8)- porque da a entender que es un error terminológico, y que ambos órganos llaman renta ficticia a lo que es renta potencial. La STC 295/2006 declara la inconstitucionalidad del párrafo primero del art. 34.b) de la Ley 18/1991, al ser contraria a la igualdad porque utiliza criterios de cuantificación diferentes para manifestaciones idénticas de capacidad económica, pero se refiere siempre a una renta potencial. En relación con el IIVTNU lo esencial es la afirmación que de pasada se hace en el FJ 8 de la STC 295/2006 de que «la titularidad de bienes inmuebles no arrendados exterioriza la existencia de una renta potencial -que no ficticia, como afirman tanto el órgano judicial planteante de la cuestión como el Fiscal General del Estado-». En contra de la opinión del TSJ del País Vasco que es quien plantea la cuestión de inconstitucionalidad y del Fiscal General del Estado, el Tribunal Constitucional deja claro que una cosa es una renta potencial, que es gravable, y otra una renta ficticia, sobre la que no se pronuncia.

Ciñéndonos ahora al gravamen de las rentas ficticias - no de las rentas potenciales a las que nos acabamos de referir-, el Tribunal Constitucional considera que el gravamen de una plusvalía inmobiliaria ficticia, es decir, irreal, es una ficción. Las SSTC 26/2017 y 37/2017, que enjuician la posible inconstitucionalidad de las Normas Forales que regulan la determinación de la base imponible del IIVTNU en Guipúzcoa y Álava (idénticas a las del TRLRH) admiten que no es posible una interpretación salvadora de la norma que permita al contribuyente probar en contra del incremento de valor que resulta de los criterios legales, pues «en el caso analizado estamos en presencia de una auténtica ficción jurídica conforme a la cual la mera titularidad de un terreno de naturaleza urbana genera, en todo caso, en su titular, al momento de su transmisión y al margen de las circunstancias reales de cada supuesto, un incremento de valor sometido a tributación, respecto del cual la norma no permite acreditar un resultado diferente al resultante de la aplicación de las reglas de valoración que contiene» (FJ 6 de la STC 26/2017 y FJ 4.e) de la STC 37/2017). En el mismo sentido el FJ 3 de la STC 59/2017 argumenta que «el tratamiento que los preceptos cuestionados de la Ley reguladora de haciendas locales [107.1. 107.2.a) y 110.4 LHL] otorgan a los supuestos de no incremento, o incluso de decremento, en el valor de los terrenos de naturaleza urbana, gravan una renta ficticia en la medida en 
REALA. Nueva Época - N. ${ }^{\circ}$ 8, noviembre 2017 - ISSN: 1989-8975 - DOI: 10.24965/reala.v0i8.10445 - [Págs. 147-163]

Los incrementos de valor inconstitucionales en el Impuesto sobre el Incremento de Valor de los Terrenos de Naturaleza Urbana

Fernando Casana Merino

que, al imponer a los sujetos pasivos del impuesto la obligación de soportar la misma carga tributaria que corresponde a las situaciones de incrementos derivados del paso del tiempo, está sometiendo a tributación situaciones inexpresivas de capacidad económica...».

El gravamen de rentas ficticias no es nuevo en el ámbito tributario. Las normas que regulan la estimación objetiva pueden tener como resultado que en el IRPF se graven rentas empresariales aunque el empresario haya tenido pérdidas reales. Lo mismo cabe decir del régimen simplificado en el IVA, en el que el IVA devengado por operaciones corrientes es el resultado de la aplicación de los módulos con independencia de las ventas reales, o el régimen especial de las empresas navieras, en el que la base imponible del Impuesto sobre Sociedades se determina por la aplicación de unos coeficientes en función de las toneladas de registro neto del buque (un número de euros diario por cada 100 toneladas) (artículos 113 a 117 de la Ley 27/2014, del Impuesto sobre Sociedades). No obstante, en estos tres casos últimos, el régimen que permite el gravamen de rentas ficticias es opcional para el obligado tributario, que siempre puede determinar su renta en estimación directa. En el IIVTNU no hay opción alguna, los preceptos que permiten la determinación de la base imponible de forma objetiva son de aplicación a todos los casos.

Queda claro, por tanto, que las normas objetivas para la determinación de la base imponible del IIVTNU constituyen una ficción jurídica, que, en ningún caso, admite prueba en contrario. Para determinar si esa ficción vulnera el principio de capacidad económica, el Tribunal Constitucional alude a su doctrina tradicional sobre el alcance de dicho principio mantenida en sentencias anteriores. La doctrina del Tribunal Constitucional sobre el principio de capacidad económica recogido en el art. $31 \mathrm{CE}$ puede resumirse en los siguientes puntos:

1. ${ }^{\circ}$ El legislador puede establecer impuestos que, sin desconocer o contradecir el principio de capacidad económica, estén orientados al cumplimiento de fines o a la satisfacción de intereses públicos que la Constitución preconiza o garantiza (entre otras, SSTC 233/1999 -FJ 14- y 193/2004 -FJ 5-). Por tanto, es constitucional que el legislador establezca un impuesto como el IIVTNU orientado a conseguir que la comunidad participe en la acción urbanística que generan los entes públicos, dando así cumplimiento al art. 47 párrafo segundo de la Constitución.

2. Para dar cumplimiento al principio de capacidad económica basta con que «dicha capacidad económica exista, como riqueza o renta real o potencial en la generalidad de los supuestos contemplados por el legislador al crear el impuesto, para que aquél principio constitucional quede a salvo» (SSTC 26/2017 -FJ 3-, 37/2017 -FJ 3-, y 59/2017 -FJ 3-).

3. ${ }^{\circ}$ El legislador, en ningún caso, puede «establecer un tributo tomando en consideración actos o hechos que no sean exponentes de una riqueza real o potencial o, lo que es lo mismo, en aquellos supuestos en los que la capacidad económica gravada por el tributo sea, no ya potencial, sino inexistente, virtual o ficticia» (SSTC 37/2017 -FJ 3-, y 59/2017 -FJ 3-).

La capacidad económica que se pretende gravar en el IIVTNU es la renta en forma de ganancia patrimonial obtenida por el propietario de un terreno durante el período de generación de la plusvalía. Esta renta que se grava en el IIVTNU nunca puede ser una renta potencial, pues no se gravan plusvalías latentes que el sujeto puede o no realizar dependiendo de si transmite o no el terreno. En el IIVTNU siempre se deben gravar plusvalías reales y efectivas que se ponen de manifiesto como consecuencia de una alteración patrimonial (transmisión del dominio o constitución o transmisión de derechos reales de goce). Por tanto, si como consecuencia del método objetivo de cálculo de la base se grava un incremento de valor irreal, se está sometiendo a tributación una renta ficticia y, por tanto, una capacidad económica inexistente o ficticia.

\section{El principio de capacidad económica, además de ser un criterio inspirador del sistema tributario opera singularmente respecto de cada persona}

De acuerdo con la doctrina del Tribunal Constitucional, el principio de capacidad económica tiene un doble sentido al ser aplicado, pues es «fundamento» de la tributación y «medida» de la tributación. En este segundo sentido, el principio de capacidad económica, como «medida» de la tributación o como «criterio» de graduación de la misma no se relaciona con una figura en particular sino con el conjunto de sistema tributario (STS 26/2017 -FJ 2-). Pero el principio capacidad económica es también «fundamento» de la tributación «que, a diferencia de otros principios (como, por ejemplo, el de progresividad), opera singularmente respecto de cada persona» (SSTC 19/1987, -FJ 3-, 193/2004 -FJ 5- y 26/2017 -FJ 2-). La capacidad económica es exigible en cada relación jurídica tributaria concreta, pues como señala la STC 26/2017 «el hecho de que el 
REALA. Nueva Época - N. ${ }^{\circ}$ 8, noviembre 2017 - ISSN: 1989-8975 - DOI: 10.24965/reala.v0i8.10445 - [Págs. 147-163]

Los incrementos de valor inconstitucionales en el Impuesto sobre el Incremento de Valor de los Terrenos de Naturaleza Urbana

Fernando Casana Merino

Constituyente no haya precedido el principio de capacidad de un artículo ("la") sino de un adjetivo posesivo ("su"), lo asocia inexcusablemente también al sujeto» (FJ 2). En definitiva, todo tributo al ser aplicado ha de gravar una manifestación de riqueza real o potencial, y vulnera el principio de capacidad económica una regulación que permita gravar riquezas meramente virtuales o ficticias. Si el IIVTNU permite gravar plusvalías ficticias vulnera el principio de capacidad económica a que se refiere el art. 31.1 CE cuando establece que «todos contribuirán al sostenimiento de los gastos públicos de acuerdo con su capacidad económica...».

\section{LA DECLARACIÓN DE INCONSTITUCIONALIDAD DE LAS NORMAS QUE REGULAN LA DETERMINACIÓN DE LA BASE IMPONIBLE DEL IMPUESTO SOBRE EL INCREMENTO DE VALOR DE LOS TERRENOS DE NATURALEZA URBANA CUANDO GRAVEN UNA CAPACIDAD ECONÓMICA FICTICIA}

\section{La primera advertencia sobre la posible inconstitucionalidad de la regulación de la base imponible del IIVTNU: la STC 221/1992}

El Tribunal Constitucional analiza por primera vez la constitucionalidad del IIVT en la Sentencia 221/1992, de 11 de diciembre. La STC 221/1992 resuelve sobre la posible inconstitucionalidad del IIVT regulado por TRRL aprobado por el R. D.-Legislativo 781/1986. El art. art. 355.1 del TRRL definía la base imponible por la diferencia entre el valor corriente en venta del terreno al comenzar y al terminar el período de la imposición (art. 355.1), y «tanto el valor corriente en venta al terminar el período de imposición, o valor final, como el valor inicial del terreno se determinan mediante los tipos unitarios del valor corriente en venta de los terrenos enclavados en el término municipal, fijados periódicamente por los Ayuntamientos» (FJ 3 de la STC 221/1992). En el sistema instaurado por el TRRL no se preveía la aplicación obligatoria de coeficientes sobre el valor en venta del terreno con la finalidad de evitar el gravamen de plusvalías ficticias debidas exclusivamente a la inflación o desvalorización monetaria. Lo que sí hizo el art. 355 TRRL es autorizar al Gobierno para que adoptase por razones de política económica medidas de corrección monetaria (coeficientes) para la determinación del valor inicial. No obstante, ni establecía cuándo el Gobierno debería adoptar estas medidas (su adopción se efectuaba, en su caso, por razones de oportunidad), ni decía qué rango debía tener la disposición que aprobase los coeficientes de actualización del valor inicial del terreno.

A pesar de que el TRRL no establecía una corrección obligatoria de los valores para adaptarlos a la inflación, la STC 221/1992 no consideró inconstitucional el art. 355.1 TRRL, porque el gravamen de plusvalías ficticias no sería debido a la inadecuada redacción del TRRL que, al menos, establece un sistema que posibilita la corrección, sino que sería imputable a la inactividad del Gobierno. En la STC 221/1992 ya se advierte que a juicio del TC, si un sistema, como ocurre con el actual del TRLRHL, no prevé medidas que corrijan la desvalorización monetaria permitiendo el gravamen de plusvalías ficticias, podría ser inconstitucional por vulnerar el principio de capacidad económica.

\section{La inconstitucionalidad de las normas que regulan la base imponible del IIVTNU cuando su aplicación suponga el gravamen de plusvalías ficticias: las SSTC 26/2017, 37/2017 y 59/2017}

La inconstitucionalidad de las normas que regulan la base imponible del actual IIVTNU es declarada en las SSTC 26/2017, 37/2017 y 59/2017. Todas ellas han sido dictadas como consecuencia del planteamiento de cuestiones de inconstitucionalidad. La STC 26/2017 declara la inconstitucionalidad de diversos preceptos de la Norma Foral de Guipúzkoa, la STC 37/2017 la inconstitucionalidad de la Norma Foral de Álava y la STC 59/2017, los preceptos correspondientes a la base imponible del IIVTNU en el TRLRHL.

Las tres SSTC que acabamos de citar siguen la misma línea y reproducen los mismos argumentos. Afirma el Tribunal Constitucional que la regulación de la base imponible del IIVTNU, tanto en las Normas Forales de Guipúzcoa y Álava como en el TRLRHL vulnera la capacidad económica, pues somete a tributación una renta no ya potencial, sino irreal (SSTC 26/2017 -FJ 3- y STC 59/2017 -FJ 3-). Expresa textualmente el FJ 3 de la STC 59/2017 que, aunque el objeto del IIVTNU nominalmente es el incremento de valor, «el gravamen, sin embargo, no se anuda necesariamente a la existencia de ese "incremento" sino a la mera titularidad del terreno durante un período de tiempo computable que oscila entre uno (mínimo) y veinte años (máximo). Por consiguiente, basta con ser titular de un terreno de naturaleza urbana para que se anude a esta circunstancia, como consecuencia inseparable e irrefutable, un incremento de valor sometido a tributa- 
REALA. Nueva Época - N. ${ }^{\circ}$ 8, noviembre 2017 - ISSN: 1989-8975 - DOI: 10.24965/reala.v0i8.10445 - [Págs. 147-163]

Los incrementos de valor inconstitucionales en el Impuesto sobre el Incremento de Valor de los Terrenos de Naturaleza Urbana

Fernando Casana Merino

ción que se cuantifica de forma automática». La consecuencia de aplicar una regulación como la hasta ahora vigente es que «se está sometiendo a tributación situaciones inexpresivas de capacidad económica» (FJ 3 de la STC 59/2017), por lo que se declaran inconstitucionales y nulos los artículos 107.1 y 107.2.a) y 110.4 LHL (FJ 5 de la STC 59/2017).

\section{La peculiar forma de declarar la inconstitucionalidad de las normas que regulan la base imponible del IIVTNU: son inconstitucionales pero solo en función del resultado de su aplicación}

Las SSTC 26/2017 -FJ 7-, 37/2017 -FJ 5- y 59/2017 -FJ 3-, declaran inconstitucionales los preceptos que determinan el cálculo de la base imponible del IIVTNU, pero «solo en la medida en que no han previsto excluir del tributo las situaciones inexpresivas de capacidad económica por inexistencia de incrementos de valor». El Tribunal Constitucional declara, por tanto, la inconstitucionalidad de la regulación de la base imponible del IIVTNU pero siempre que su aplicación conlleve el gravamen de plusvalías ficticias, nunca en los demás casos. Esta declaración de inconstitucionalidad limitada a los efectos de la aplicación de la norma es expuesta con más claridad en el FJ 5 de la STC 59/2017 que comienza por afirmar que el IIVTNU «no es con carácter general, contrario al Texto Constitucional», sino que «lo es únicamente en aquellos supuestos en que somete a tributación situaciones inexpresivas de capacidad económica, esto es, aquellas que no presentan aumento de valor del terreno al momento de la transmisión». Concluye la argumentación del FJ 5 de la STC 59/2017, que «deben declararse inconstitucionales y nulos, en consecuencia, los arts. 107.1 y 107.2.a) LHL "únicamente en la medida en que someten a tributación situaciones inexpresivas de capacidad económica (SSTC 26/2017 -FJ 7- y 37/2017 -FJ 5-)"». En el apartado siguiente, y aunque su inconstitucionalidad no ha sido puesta en duda por el órgano judicial que plantea la cuestión, el mismo FJ 5 de la STC 59/2017 declara por conexión la inconstitucionalidad del art. 110.4 LHL. El citado art. 110.4 TRLRHL no se explica de forma autónoma sino por relación con los arts. 107.1 y 107.2.a) TRLRHL, pues limita las competencias comprobadoras de los ayuntamientos en los casos de autoliquidación a constatar que se ha efectuado una correcta aplicación de las normas que ahora se han declarado inconstitucionales, «sin que puedan atribuirse valores, bases o cuotas diferentes de los resultantes de tales normas». Concluye el Tribunal Constitucional en el apartado b) del FJ 5 de la Sentencia 59/2017 que «por consiguiente debe declararse inconstitucional y nulo el art. 110.4 LHL al impedir a los sujetos pasivos que puedan acreditar la existencia de una situación inexpresiva de capacidad económica (SSTC 26/2017 -FJ 7-y 37/2017 -FJ 5-)».

La doctrina ha puesto de relieve lo difícil que resulta «aceptar que se declare la inconstitucionalidad de una norma en función de lo que resulte de su aplicación» (MENÉNDEZ MORENO, 2017: 10). No se declara la inconstitucionalidad de las normas cuestionadas porque per se son contrarias al principio de capacidad económica, sino en la medida en que gravan situaciones «que no presentan aumento del valor del terreno al momento de la transmisión» [STC 59/2017, FJ 5.a)]. El Tribunal Constitucional declara la inconstitucionalidad de los preceptos que regulan la base imponible del IIVTNU en función de los efectos que produzca su aplicación. Por tanto, los preceptos del TRLRHL y sus homólogos de las Normas Forales no han sido expulsados del ordenamiento en cualquier caso. La inconstitucionalidad solo se produce cuando la aplicación del precepto que permite el cálculo de la base imponible conduce a someter a tributación terrenos que no presentan un aumento de valor en el momento de la transmisión. Dos cuestiones problemáticas suscita esta doctrina que hace depender la inconstitucionalidad de una norma de los efectos que pueda producir su aplicación y que ponen de manifiesto que la misma no favorece la seguridad jurídica.

En primer lugar, el juicio sobre si la norma en cuestión es o no inconstitucional depende de que el terreno no haya aumentado de valor, lo que obliga a comparar valores en dos momentos distintos. Esta comparación plantea el problema de que no está determinado con qué valor hay que comparar el valor del terreno en el momento del devengo (con el valor catastral en el momento de iniciarse el cómputo de la plusvalía, con el valor de mercado, con el que resulta de un procedimiento de comprobación de valores o con cualquier valor que sea objeto de prueba). Llegados a este punto, la cuestión se reduce a una cuestión de prueba, y de acuerdo con las normas generales sobre carga de la prueba «quien haga valer su derecho deberá probar los hechos constitutivos del mismo» (art. 105.1 de la Ley General Tributaria). En mi opinión, si el obligado tributario prueba por cualquier medio que el terreno no ha aumentado de valor, deberá ser la Administración la que pruebe en contra de dichas pretensiones para poder aplicar los preceptos del TRLRHL. ALÍAS CANTÓN ha manifestado que el valor que consta en la escritura pública de transmisión puede considerarse como una declaración, debiendo tenerse en cuenta que según el art. 108.4 de la Ley General Tributaria, los 
REALA. Nueva Época - N. ${ }^{\circ}$ 8, noviembre 2017 - ISSN: 1989-8975 - DOI: 10.24965/reala.v0i8.10445 - [Págs. 147-163]

Los incrementos de valor inconstitucionales en el Impuesto sobre el Incremento de Valor de los Terrenos de Naturaleza Urbana

Fernando Casana Merino

datos y elementos de hecho declarados y demás documentos presentados se presumen ciertos para los obligados tributarios. La consecuencia de la aplicación de las normas de la prueba a la escritura pública, según ALÍAS CANTÓN, es que «si la Administración tributaria, quiere desvirtuar la veracidad del contenido de dicho documento público, obligatoriamente deberá desplegar su actividad probatoria, de conformidad con lo preceptuado en los artículos 105 y 106 de la LGT. Lo que no puede hacer la Administración Tributaria, es rechazar de plano el contenido de dicho documento público, sin realizar actividad probatoria alguna en contra» (ALÍAS CANTÓN, 2017: 33). A mi juicio, la escritura pública es un medio de prueba más, pero no es un medio de prueba indubitado. Una vez presentada y efectuada la declaración poniendo de relieve la inexistencia de plusvalía según resulta de la escritura, este medio de prueba, como cualquier otro que sea aducido, podrá ser apreciado por la Administración en el procedimiento que corresponda (de declaración y liquidación o de comprobación). La apreciación de la prueba presentada en el procedimiento tributario correspondiente incumbe al ayuntamiento, que es quien tiene el impulso del procedimiento. El resultado de esa apreciación será notificado al contribuyente, el cual se verá asistido por todos los medios de defensa que se le reconocen primero en la vía administrativa y después en la vía judicial (por ejemplo, la posibilidad de instar una tasación pericial contradictoria). En la vía judicial, la prueba de la inexistencia del incremento de valor será apreciada por los Tribunales de acuerdo con las normas del Código Civil y de la Ley de Enjuiciamiento Civil.

Las SSTC 26/2017, 37/2017 y 59/2017 suscitan una segunda cuestión en relación con los requisitos que permiten inaplicar las normas del TRLRHL. Solo se declaran inconstitucionales las normas en la medida en que su aplicación tenga como consecuencia el gravamen de plusvalías ficticias, es decir, solo cuando el terreno no haya aumentado de valor (que haya disminuido o se haya mantenido con un valor idéntico al inicial). Por tanto, cuando el terreno haya aumentado algo de valor, pero el incremento o plusvalía sea inferior al que resulta de las normas del TRLRHL, el Tribunal Constitucional no dice expresamente que la norma sea inconstitucional. No obstante, a mi juicio, está implícito en la doctrina de las SSTC 26/2017, $37 / 2017$ y 59/2017 que lo que se pretende con la declaración de inconstitucionalidad es impedir que se graven incrementos de valor inexistentes o irreales, y la irrealidad puede ser de la totalidad del incremento o de parte de él. Cuando el terreno ha aumento de valor pero no tanto como el que resulta de la aplicación de las normas legales, siguiendo la doctrina del Tribunal Constitucional, la aplicación taxativa de dichas normas supondría gravar situaciones inexpresivas de capacidad económica y, por tanto, su aplicación resulta tan inconstitucional como cuando se grava un terreno que ha disminuido de valor. A nuestro juicio, no es necesario que el Tribunal Constitucional diga expresamente que la norma también es inconstitucional cuando el terreno no ha aumentado de valor tanto como el incremento que resulta de la aplicación del TRLRHL, pues en ambos casos (ningún incremento o un incremento inferior al que resulta de la aplicación de la norma) se está gravando una plusvalía inexistente y ese acto de gravamen vulnera el principio de capacidad económica.

\section{La imprescindible modificación del Texto Refundido de la Ley Reguladora de las Haciendas Locales y la solución de las situaciones generadas por la inconstitucionalidad hasta tanto se produzca la modificación}

La situación en que ha quedado el TRLRHL en relación con el IIVTNU exige la modificación de la citada norma legal. El apartado c) del FJ 5 de la STC 59/2017 así lo reconoce, afirmando acertadamente que una vez expulsados del ordenamiento jurídico los preceptos comentados «en los términos señalados», «la forma de determinar la existencia o no de un incremento susceptible de ser sometido a tributación es algo que solo corresponde al legislador» (en el mismo sentido SSTC 26/2017 -FJ 7- y 37/2017 -FJ 5-).

Los Territorios Forales han aprobado normas de adaptación a la jurisprudencia constitucional que modifican la base imponible del IIVTNU. Han sido aprobados los Decretos de Guipúzcoa (de 28 de marzo, Boletín Oficial de Guipúzkoa de 31 de marzo), Álava (de 28 de marzo, Boletín Oficial de Álava de 5 de abril) y de Vizcaya (de 20 de junio, Boletín Oficial de Bizkaia de 22 de junio) que modifican las normas forales que regulan el IIVTNU. En los tres Decretos normativos forales se establece que para que nazca la obligación tributaria será necesaria la existencia de incremento de valor, y el incremento de valor se determina por la comparación entre el valor de adquisición y el valor de transmisión. Por tanto, la inexistencia de plusvalía se configura como un supuesto de no sujeción, lo que de acuerdo con la aplicación taxativa de la normativa hasta ahora en vigor resultaba imposible. Cuando nace la obligación tributaria porque hay incremento de valor, la base imponible del IIVTNU, según las normas forales reformadas, se determinará de acuerdo con la norma foral tradicional anterior a las SSTC. 
Para determinar si existe o no incremento de valor, las normas forales modificadas de Álava y Guipúzcoa se remiten a los valores de adquisición y transmisión, que serán los que deberían tenerse en cuenta a efectos de los respectivos impuestos que recaen sobre la transmisión del terreno. Por tanto, en Álava y Guipúzcoa la existencia o no de incremento de valor se determina, en función de los valores que deberían tenerse en cuenta a efectos del Impuesto sobre Transmisiones Patrimoniales y Actos Jurídicos Documentados o del Impuesto sobre Sucesiones y Donaciones, según que la respectiva transmisión sea onerosa o gratuita. En los casos en que no pueda determinarse la existencia o, en su caso, inexistencia de incremento de valor de los terrenos, las normas forales dicen que se utilizará como referencia el valor real, que, por otra parte, no difiere del valor fijado a efectos del Impuesto sobre Transmisiones Patrimoniales y Actos Jurídicos Documentados o del Impuesto sobre Sucesiones y Donaciones, por lo que la regla no añade nada a las ya citadas.

El Decreto Foral Normativo 3/2017 de Bizkaia, de 20 de junio, difiere en algo de los anteriores, pues para determinar si existe o no incremento de valor «los valores de adquisición y transmisión serán los que consten en los correspondientes documentos acreditativos de los títulos de propiedad», con lo que se admite el valor de la escritura como medio de prueba acreditativo del valor del terreno en el momento de la transmisión/adquisición.

En definitiva, las normas forales de Guipúzcoa y Álava se remiten a los valores que se utilicen en los impuestos estatales que gravan la transmisión del terreno para determinar si existe o no incremento de valor. En Vizcaya los valores de adquisición o de transmisión serán los que consten en los documentos acreditativos de los títulos de propiedad, con lo que la modificación de la norma foral se efectúa en un sentido claramente favorable al contribuyente.

Por lo que respecta a la situación en que queda el IIVTNU en los ayuntamientos que se rigen por el TRL$\mathrm{RHL}$, es indudable que va a ser necesario proceder a su modificación. La nueva regulación puede suprimir totalmente el IIVTNU, o sustituirlo por otro de naturaleza similar. El profesor MARÍN-BARNUEVO FABO expone y comenta las distintas opciones legislativas que se abren ante una posible supresión total del IIVTNU (compensar las pérdidas de los ayuntamientos como consecuencia de la supresión del IIVTNU, incorporar la capacidad recaudatoria del IIVTNU al IBI, establecer un gravamen complementario del ITPO), y comparte la opinión de quienes consideran herido de muerte al IIVTNU, «en tanto resulta prácticamente imposible adaptar su regulación al mandato contenido en el fallo de las sentencias analizadas y, al tiempo, conseguir que la gestión del IIVTNU siga siendo sencilla para los ayuntamientos» (MARÍN-BARNUEVO FABO, 2017: 44).

En el mismo sentido, también recientemente, el profesor PEDREIRA ha argumentado que el IIVTNU «debería ser eliminado ya que las ganancias, de haberse generado, ya están gravadas en los impuestos sobre la renta y sucesorios y no tiene sentido la existencia de un tributo que no grava las mismas, para no incurrir en doble imposición, sino una ficción» (PEDREIRA MENÉNDEZ, 2017: 138). Estamos totalmente de acuerdo con el profesor PEDREIRA en que si se mantiene el IIVTNU debe ser para gravar un incremento de valor y, es obvio que, en tal caso, se produce una doble imposición con las plusvalías inmobiliarias gravadas por el Impuesto sobre Sociedades o el IRPF. No obstante, dobles imposiciones se dan en nuestro sistema interno en muchos supuestos, no están prohibidas legalmente salvo en algunos casos, y deben tomarse como una imprecisión técnica.

En mi opinión, a pesar de que hay una doble imposición interna clarísima, va a ser muy difícil que se llegue a la supresión total del IIVTNU y que este no sea sustituido por otro similar, dada la precariedad de la hacienda municipal y el grado de autonomía que supone para los municipios poder regular en parte este Impuesto, así como gestionarlo en su totalidad. El Informe de la Comisión de Expertos para la revisión del Modelo de Financiación Local de 26 de julio de 2017 propone la supresión del actual IIVTNU y su sustitución por un Impuesto Municipal sobre Plusvalías Inmobiliarias (en adelante IMPI), en el que la base se determinaría por la diferencia entre el valor real del inmueble en la transmisión y su valor de adquisición ${ }^{6}$. El valor de adquisición, según los redactores del Informe, debería seguir los criterios de los impuestos personales sobre la renta (IRPF e Impuesto sobre Sociedades) e incluiría el importe real de la adquisición más el coste de las inversiones y mejoras efectuadas, así como los gastos y tributos inherentes a aquélla. Por otra parte, según el Informe de la Comisión de Expertos, el nuevo IMPI no distinguiría entre valor del suelo y valor de la construcción, sino que gravaría, igual que el IRPF o el Impuesto sobre Sociedades, el valor total del inmueble.

6 Informe de la Comisión de Expertos para la revisión del Modelo de Financiación Local de 26 de julio de 2017 , disponible en www.minhafp.gob.es [consulta realizada el 26 de octubre de 2017]. 
REALA. Nueva Época - N. ${ }^{\circ}$ 8, noviembre 2017 - ISSN: 1989-8975 - DOI: 10.24965/reala.v0i8.10445 - [Págs. 147-163]

Los incrementos de valor inconstitucionales en el Impuesto sobre el Incremento de Valor de los Terrenos de Naturaleza Urbana

Fernando Casana Merino

El Informe prevé también que el nuevo IMPI debería corregir los efectos de la inflación acumulada desde la fecha de adquisición del inmueble o de realización de las mejoras o inversiones.

El profesor MARÍN-BARNUEVO FABO explica las diferentes opciones que pueden adoptarse para regular la base imponible de un nuevo impuesto sobre las plusvalías inmobiliarias de carácter local. La base imponible, según el citado profesor, puede calcularse mediante los siguientes sistemas: a) Mediante comparación entre los precios declarados en la adquisición y transmisión del inmueble. b) Mediante la traslación al IIVTNU de los cálculos realizados en el IRPF para cuantificar las ganancias de patrimonio. c) Mediante la traslación al IIVTNU del concepto de valor real o valor de mercado previsto en el ITPO. d) Mediante la comparación entre el valor catastral en los momentos de adquisición y enajenación. e) Mediante la comparación entre el "valor catastral referenciado» en el momento de la adquisición y en el de la enajenación (MARíNBARNUEVO FABO, 2017:33).

El profesor VARONAALABERN, se muestra partidario de calcular la plusvalía gravable mediante un sistema similar al de los impuestos personales sobre la renta, aunque manteniendo que se grave solo el valor del suelo. En su opinión, debería partirse de la plusvalía neta que se derivase de la aplicación de las reglas del IRPF o del Impuesto sobre Sociedades, y posteriormente reducirla porcentualmente en función del valor que represente el terreno en relación con el total valor catastral inmueble (valor del terreno más valor de la construcción). A la plusvalía reducida, añade el profesor VARONA, «aplicarían los Ayuntamientos -dentro de un límite trazado en la ley- el tipo de gravamen que estimasen oportuno y que habría de ser necesariamente bajo, a fin de aproximar (por exceso o por defecto) su capacidad recaudatoria a la actual.... De acuerdo con este planteamiento, cuando el inmueble arrojara una minusvalía, la cuota tributaria del impuesto local sería cero» (VARONA ALABERN, 2010: 88).

Una variante de la doctrina expuesta por el profesor VARONA es la que aporta LUQUE MATEO, para quien el valor de transmisión sería «el importe por el que efectivamente se hubiera efectuado y en las operaciones lucrativas el valor normal de mercado, siempre que, en ambos casos, tales valores no fueran inferiores a los que resultarían de la aplicación de las normas de valoración de inmuebles de los Impuestos sobre Transmisiones Patrimoniales y Actos Jurídicos Documentados (...) y sobre Sucesiones y Donaciones, incorporando la posibilidad establecida en este ámbito de ejercitar el derecho a la tasación pericial contradictoria. Y como valor de adquisición se tomaría el que constara en el título de la correspondiente operación (normalmente contenido en la escritura pública), con las actualizaciones reguladas en la normativa aplicable al caso» (LUQUE MATEO, 2014: 1.589-1.590)

Desde luego la aplicación de un sistema similar al del IRPF o al del Impuesto sobre Sociedades, que es el que se propone por la Comisión de Expertos y la doctrina ya expuesta, o utilizar el valor real como se hace en el Impuesto sobre Transmisiones Patrimoniales y Actos Jurídicos Documentados y en el Impuesto sobre Sucesiones y Donaciones, son métodos que aportan muchas garantías, pero también son los que pueden generar mayor conflictividad, pues si el ayuntamiento no acepta los valores declarados, la plusvalía habrá de determinarse en un proceso contradictorio (administrativo o judicial). Puesto que en muchos ayuntamientos la gestión municipal no puede soportar un sistema que genere mucha conflictividad, parece lógico, introducir algún elemento de cálculo que sea objetivo y que no todo tenga que ser objeto de prueba. PADILLA RUIZ dice que se podría «acudir a las estadísticas oficiales sobre el valor de mercado del suelo urbano como las que se publican en el Boletín estadístico del Ministerio de Fomento» (PADILLA RUIZ, 2017, 9: 139). También podrían adoptarse otros sistemas, como la publicación de unas tablas similares a las que utilizan algunas CCAA en el Impuesto sobre Transmisiones Patrimoniales y Actos Jurídicos Documentados o en el Impuesto sobre Sucesiones y Donaciones, y que parten de la multiplicación del valor catastral por un coeficiente. También podría crearse un sistema totalmente nuevo similar al de la estimación objetiva mediante módulos en el IRPF. Por tanto, no hay que desdeñar la adopción de sistemas intermedios en los sea posible la objetivación de algunos datos y que en función de todos ellos -los objetivados y los que pueden ser objeto de contradicción- se determine el incremento gravable.

En cualquier caso, hay que tener en cuenta que hasta tanto no se modifique el TRLRHL, y también después de su modificación, los incrementos de valor inexistentes o ficticios no podrán ser gravados. Esto supone que el obligado tributario, con independencia del sistema de cálculo de la base que se adopte y mientras se adopta alguno, debe tener siempre la posibilidad de probar que el incremento realmente sufrido por el terreno ha sido nulo o inferior al que resulta de la aplicación de las normas legales. Por tanto, el sistema legal que se apruebe solo será aplicable si el obligado tributario no prueba que el terreno no se ha incrementado de valor. A mi juicio, y por las razones expuestas con anterioridad, de los argumentos de 
la jurisprudencia constitucional también se deduce que cuando el incremento es inferior al que resulta de las normas legales y así se prueba, debe gravarse el incremento real y no el que resulte de los preceptos del TRLRHL.

Por lo que respecta a la doble imposición que se produce entre el IIVTNU y los impuestos personales sobre la renta, el Informe de la Comisión de Expertos prevé que sea eliminada permitiendo que el nuevo IMPI sea deducible «de la base imponible de los distintos impuestos estatales que gravan las plusvalías inmobiliarias ${ }^{7}$. A mi juicio, la eliminación de la doble imposición puede hacerse mediante deducciones de base a base o de cuota a cuota. Es decir, de la base del impuesto personal sobre la renta podría deducirse la plusvalía gravada por el IMPI -aspecto este al que parece referirse el Informe de la Comisión de Expertos-, pero también podría deducirse de la cuota de dicho impuesto personal la cuota pagada al ayuntamiento por el impuesto sobre la plusvalía municipal.

Por último, quedan por analizar los problemas de Derecho transitorio que genera la declaración de inconstitucionalidad del IIVTNU. Las SSTC 26/2017, 37/2017 y 59/2017 no dicen nada en cuanto al alcance temporal de sus efectos. Por lo que respecta a los hechos imponibles que se realicen desde que han sido publicadas las SSTC, la cuestión está relativamente clara: el obligado tributario sigue teniendo obligación de declarar con arreglo a la redacción actual del TRLRHL, y en los casos en que se graven plusvalías inexistentes, podrá recurrir la liquidación o solicitar la rectificación de la autoliquidación. Para evitar que las liquidaciones entren en apremio, el obligado tributario debe paralizar previamente la ejecución mediante la prestación de garantía suficiente o efectuar el ingreso de la deuda tributaria y quedar a expensas de una futura devolución de ingresos indebidos. Las normas forales de modificación incorporan sus respectivas disposiciones transitorias. Tomando como referencia algunas de las soluciones que adopta el Decreto Foral Normativo 3/2017 de Bizkaia, de 20 de junio, aunque teniendo en cuenta que los efectos de la STC 57/2017 son inmediatos sin necesidad de que se modifique el TRLRHL, la situación en las CCAA de régimen común es la siguiente:

$1 .^{\circ}$ Las liquidaciones y autoliquidaciones firmes correspondientes a las obligaciones tributarias devengadas con anterioridad a la publicación de la STC 57/2017 seguirán el procedimiento recaudatorio que corresponda sin que proceda ni la rectificación, ni la devolución de ingresos indebidos.

$2 .^{\circ}$ Las liquidaciones o autoliquidaciones que se encuentren recurridas o en vías de rectificación con anterioridad a la publicación de la STC 57/2017, aunque se refieran a obligaciones devengadas con anterioridad a dicha fecha, a mi juicio permiten iniciar un procedimiento de devolución de ingresos indebidos si se han gravado plusvalías inexistentes y la deuda ha sido ingresada. En el caso de que no se haya ingresado ninguna deuda tributaria, la liquidación que resuelva el recurso o el procedimiento de rectificación de la autoliquidación debe tener en cuenta que solo pueden gravarse incrementos de valor que sean reales.

3. ${ }^{\circ}$ Los hechos imponibles correspondientes a las obligaciones tributarias devengadas con posterioridad a la publicación de la STC 57/2017 deberán declararse con arreglo a la normativa declarada inconstitucional, y, en su caso, posteriormente recurrir la liquidación o solicitar la rectificación de la autoliquidación. Simultáneamente a la presentación del recurso o la solicitud de rectificación habrá de pagarse la deuda tributaria que resulte o suspender la ejecución del acto mediante la prestación de garantía suficiente. En el caso de que se haya satisfecho el importe de la deuda tributaria, si el incremento gravado no es real, conjuntamente con el recurso contra la autoliquidación o conjuntamente con la solicitud de rectificación de la autoliquidación, debe solicitarse la devolución de los ingresos indebidamente realizados.

\section{REFERENCIAS BIBLIOGRÁFICAS}

ALÍAS CANTÓN, Manuel (2017), "La escritura como prueba para acreditar la depreciación del valor a efectos del IIVTNU", Quincena Fiscal, 11: 21-34.

BRIS GÓMEZ, Rosario (2015), "IIVTNU: Sentencia del Juzgado Contencioso-Administrativo núm. 4 de Bilbao de 25 de febrero de 2015", Quincena Fiscal, 10: 147-149.

ESEVERRI MARTÍNEZ, Ernesto (1995), Presunciones legales y Derecho Tributario, Madrid, Instituto de Estudios Fiscales-Marcial Pons.

GUTIÉRREZ BENGOECHEA M., Miguel (2012), Las presunciones y ficciones en el ámbito tributario y su aplicación a las rentas societarias, Granada, Editorial Comares.

7 Informe de la Comisión de Expertos para la revisión del Modelo de Financiación Local de 26 de julio de 2017 , disponible en «www.minhafp.gob.es», pág. 48 [consulta realizada el 26 de octubre de 2017]. 
HERNÁNDEZ LAVADO, Alejo (1991), "El Impuesto Municipal sobre el Incremento de Valor de los Terrenos de Naturaleza Urbana”, en CALVO ORTEGA, R. (director), La reforma de las Haciendas Locales: 57-114, tomo II, Valladolid Lex Nova.

LUQUE MATEO, Miguel Ángel (2014), "Cuestiones problemáticas del Impuesto sobre Incremento de Valor de los Terrenos de Naturaleza Urbana”, en ADAME MARTÍNEZ, Francisco y RAMOS PRIETO, Jesús (Coordinación), Estudios sobre el Sistema Tributario Actual y la situación financiera del sector público. Homenaje al Profesor Dr. D. Javier Lasarte Álvarez: 1.571-1.603, Madrid, Instituto de Estudios Fiscales [en formato cd rom].

MARÍN-BARNUEVO FABO, Diego (2017), "Significado y alcance de la declaración de inconstitucionalidad de la regulación del IIVTNU en Guipúzcoa y Álava”, Centro de Estudios Financieros. Contabilidad y Tributación. Comentarios y casos prácticos, 409: 5-44.

MARTÍN RUIZ, Juan (2017), "A propósito del desenlace constitucional del impuesto sobre el incremento de valor de los terrenos de naturaleza urbana: La correcta interpretación del hecho imponible", en GARCíA BERRO, Florián (director), La delimitación de los elementos esenciales del tributo ante el impacto de las reformas fiscales: 51-80, Cizur Menor (Navarra), Aranzadi.

MENÉNDEZ MORENO, Alejandro (2017), "La valoración de los inmuebles urbanos o convertir el agua en vino", Quincena Fiscal, 8: 3-12.

MOCHÓN LÓPEZ, Luis (2001), El valor catastral y los impuestos sobre bienes inmuebles y sobre el incremento de valor de los terrenos de naturaleza urbana. Una aproximación al concepto de valor catastral, Granada, Comares.

ORÓN MORATALL, Germán (2010), "Capítulo V. El Impuesto sobre el Incremento de Valor de los Terrenos de Naturaleza Urbana”, en MARÍN-BARNUEVO FABO, Diego (coordinador), Los Tributos Locales, Cizur Menor (Navarra), Aranzadi.

PADILLA RUIZ, Pedro (2017), "Reflexiones en torno a la anulación parcial del Impuesto sobre el Incremento del Valor de los Terrenos de Naturaleza Urbana", Quincena Fiscal, 9: 131-139.

PEDREIRA MENÉNDEZ, José (2017), "La inconstitucionalidad parcial de la plusvalía municipal debería servir para su eliminación total”, Quincena Fiscal, 8: 133-138.

SÁNCHEZ GALIANA, José Antonio y CALATRAVA ESCOBAR, M. a Jesús (1993), "Capítulo XVI. El Impuesto sobre el Incremento de Valor de los Terrenos de Naturaleza Urbana", en FERREIRO LAPATZA, J. J. (director), Tratado de Derecho Financiero y Tributario Local: 857-892. Madrid, Diputaciò de Barcelona-Marcial Pons.

SÁNCHEZ GALIANA, Carlos M. a (2010), "La necesaria reforma tributaria de las haciendas locales: algunas consideraciones sobre la imposición municipal”, Quincena Fiscal, 9: 47-48.

VARONA ALABERN, Juan Enrique (2010), "A vueltas con la inconstitucionalidad del impuesto sobre el incremento de valor de los terrenos de naturaleza urbana”, Quincena Fiscal, 18: 65-89. 